\title{
Research on Teaching Pattern of Undergraduates Courses Based on Systemic Projects*
}

\author{
Baoyuan CHEN, Liang WANG, JingYang LIU, Zhongming LUO, Lihua WU, Bo LIU \\ The higher educational key laboratory for Measuring \& Control Technology and Instrumentations of Heilongjiang Province, \\ Harbin University of Science and Technology, Harbin 150080, China \\ chenbaoyuan@126.com
}

\begin{abstract}
Undergraduates' innovation ability is formed and developed gradually in the basic of the general practice ability and special practice ability. The study on teaching practice found the following conclusions. The students' general practice ability is the basis of the innovation ability. And the general practice ability is developed in the professional courses through the gradual participatory teaching of process. The systemic projects teaching model can effectively promote the undergraduates' practice and creativity. Besides, much more participants would benefit from the systemic projects teaching model than the declaration model based on the creative experiments. In addition, it is often the verification projects that used in the traditional teaching model. But the verification projects do no good to the initiative and creativity of the students. The research of this paper will provide an instruction for experiment teaching of the undergraduate courses.

Index Terms - undergraduate, experiment teaching of course, practical innovation ability, project guidance.
\end{abstract}

\section{Introduction}

In recent years, domestic and foreign universities put increasing emphasis on the reform of undergraduate practical teaching and actively carry out it. MIT built an activity system of practical education, including undergraduate seminars, extracurricular academics. Cambridge proposed that to improve students' ability in the general living world and the students' participation in scientific research are supported. Harvard University, Stanford University, the University of California, Berkeley and other famous universities have developed the plans on practical education and students' research. They want to educate and improve the students' practical innovation ability by implementation of the plans [1].

In China, the Ministry of Education particularly claims to promote reform and construction of undergraduate teaching. It is proposed to play more importance on the students' comprehensive quality other than the accumulation of the knowledge, to put high significance on practice and to improve the students' practical skills [2]. It is also required to improve the students' creativity by innovative practice [3]. The local education departments promptly act in response to the appeal. The creative experimental projects of undergraduate students were also operated in Heilongiiang province. In various universities, the teachers and students are advocated to declare the experiment projects. Besides, the university-level creative experimental projects of undergraduate students are setup for more opportunity in practice and creative[4].

There is a shortcoming in this teaching pattern based on the declaration of creative experiment that just a small number of students are involved and the rest of the students cannot be favored in their practice. In this case, it's a kind of elite education. The application of the projects practical teaching method will overcome this defect and can effectively promote the practice and creativity of the undergraduates[5].

\section{The Current Situation of Experiment Teaching of Undergraduate Courses}

In their four years of undergraduate study, they take the foundation courses in the first 2 years. In the third year, they begin to learn the professional courses which are compulsory. They have to pass the final examination before got the credit. Meanwhile, the students need to attend some optional courses varying with their jobs [6]. Some of the professional courses contain experimental programs. Generally, the experimental programs only take several class hours. Most of the class hours are teaching hours. For this kind of professional courses, we should firstly assign theoretical lectures and then arrange experiment programs depend on the teaching contents. The programs are performed to validate the theory. Thus, the experiment teaching and the experiment teaching usually are inseparably interconnected.

In this experiment teaching pattern of professional courses, most programs are confirmatory and each program is complete independent. Other more courses are matched with fixed and modular lab equipment. What the students know from the experiment is the connection of schematic circuits. They know nothing of the components or the circuit principle. It is a stiff form. Let alone the cultivation of practice or the creativity.

The key to make experimental teaching more effective is to activate the students' initiative and enthusiasm [7].

\section{The Design of Experiment Teaching Under the Guidance of Systemic Projects}

\section{A. The design of experimental projects}

One of the fundamental requirements of experimental teaching is to arrange suitable projects depend on the course

\footnotetext{
* This project is Heilongjiang Province College Education Engineering Projects. Grant No:JG2012010282 and JG2013010302
} 
features and the core contents. It would be better to set up the projects with systematization and moderate difficulty [8]. Of course, the project may be complicated step by step. Then the goal which is to promote the practice of students gradually achieves. At the beginning, a basic perception project should be arranged. It's the foundation of the later experiment. The students can get a preliminary understanding about the projects, such as the operation method, the modules, the basic principle and the experimental skills. Next, a systemic project will be set up depending on the rest of experiment hours. The project's difficulty and contents must correspond to the course. The systemic project is the experiment that can accomplish the separate and application features. In this procedure, you should take account of the multi-solutions of this project. To avoid the projects that can only carried out in a single solution. The class hours of course experiment are scattered which is different from the curriculum design or the design of a school year. Considering this fact, this project should be divided into several modules in terms of the needed class hours. Every module can be executed separately. And the outcome of every module should be well reserved. The last step is to conduct the systemic debugging experiment. Integrate a system using the outcome of all the modules and debug it. Now, the systemic experiment is finished. At last, collect the data and information from the systemic experiment and write the experiment report in a standard way. The report would be in teachers' desk in time. Then the teacher evaluates the grade according to the student's behavior in experiment and the quality of his report. The result is one part of his term record. It's a good measure to urge and educate the students.

\section{$B$. The management in the experiment teaching process}

Process management is an efficient management mode recognized in various fields. It has the advantages of high efficiency, timeliness and synchronization. If the target management is adopted in the experiment teaching, there must be a terrible ending. The reason is that some students are short of initiative, self-discipline or technical skills. A teacher is required to participate and supervise all the time. He can help the students in trouble. The experiment process consists of the following parts.

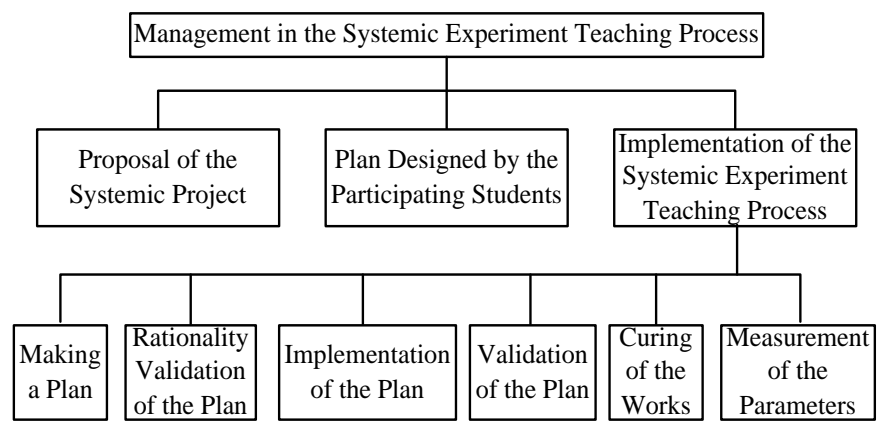

Fig. 1 Frame of the systemic experiment teaching process

\section{1) Proposal of the systemic project}

It is the teacher's job. According to the course, he makes the design objective to let the students to know the outline of the project. The project has to be designed with clear modularity so that it will be convenient to divide the class hours and to gain the interim result. At the same time, the proposed projects should have the feature of multi-solution, in order to ensure the diversity of the design to activate the enthusiasm of the students. Moreover, in order to save money and carried out easily, the kinds of the main electronic components in this project should be confined.

\section{2) Teaming up of the participating students}

After the students get the project information, they will team up with others at discretion. After class, they have to design the projects and make the proper documents in groups under the teacher's guidance.

\section{3) Implementation of the modular experiment course}

When it comes to this project, we stated earlier that the students has studied and known about the module circuits and the related electronic component. The implementation of the project will be divided into 6 parts. They are rational test of the design, project validation, module testing, module curing, inspection of curing module and measurement of experimental parameters, store after numbered.

The rational test of the design is that the teacher looks over whether the students' design is reasonable and reaches the requirement of project. If the design is unsatisfactory, the teacher will make some adjustments and corrections. In the part of project validation, the students are guided to compose and test the modular circuit with the common laboratory equipment, especially to design and implement the rational structure and layout. Because the project design has many solutions, it's the students who choose the electronic components and device. This way is helpful to the independence and organizational skills of the students. Module testing is to test the performance of the experiment module, including its functions and parameters and to adjust the parameters when it's needed. Module curing occurs in the general board, welding and curing the module that is connected and meet the requirement. This part is an essential process based on the foregoing experiment to train the ability of structure design and implementation. The practical operation skills of the student also get better. The 5th part is inspection of curing module and measurement of experimental parameter. This part contains an assessment of designed experimental modules designed. It's the key stage to judge the quality of project. Make a conclusion from the verification of design rationality and the relevant theory of the course. The last part is store after numbered. Numbered all the designed modules of the students and then stored them. They will be used to be elements of the systems at the later of the project.

In the process of modular experiment, the modules that meet the demand are ready after the operation and testing. Connect the modules and you will get the systemic design that meet the demand. 
The students are cultivated with independent design ability, modular design ideas and system quality in the experiment teaching.

\section{The Practice of Experimental Teaching Plan Based on Projects}

With the support of our university and the college, the experiment course named "Measurement and Control Circuit" using this teaching plan was practiced effectively.

Measurement and control circuit is the essential and flexible part of the measurement and control system. This course mainly consists of sensors, control circuits and actuators.

Corresponding to the course, the sensors and control circuits are the key contents of the experiment project. As this experiment course was assigned 10 class hours, we designed 2 projects, one is the basic perception project accounting for 2 class hours and the other is the systemic project accounting for 8 class hours. Considering that the systemic project carried out in 2 modules, each module takes up 4 class hours. As a result, the class hours are allocated as 2:4:4.

The first one is the basic experiment. It's designed for students to gain better understanding about the various modular circuits containing operational amplifiers, the parameters and recognition ways of electronic components. The second part is the signal conversion experiment of temperature sensor. It's also the systemic project mentioned before. This project is aim to convert the Pt100 resistance parameters which is changed with the temperature into the frequency signal that is easy to measure. This project can be divided into 2 modules. One is gaining and conversion of the original signals by sensor and the other is the electrical signal conversion. The function of the first module is to convert sensor temperature information into standard voltage signal or standard current signal. The obtained signal will be used in the second module. The module of electrical signal conversion is to realize the conversion from the standard voltage signal or standard current signal into frequency signal. This project consists of two independent modules and each module is multi-solution.

The total number of students in the experiment teaching was 262. 258 of them accomplished the whole experiment. The rest 4 students were failed for some reason. 23 kinds of schemes were designed. 246 students got the right experiment data. Therefore, 246 sets of works were qualified.
After this experiment course, we did questionnaires for the practice of the experiment course guided by projects. It was shown in the results that the students' practice and independent design ability were improved through this teaching scheme. The students got the overall and partial understanding of works design. What is more, their design skill and practice also were cultivated from modules to the system.

\section{Conclusions}

The conclusions are as follows. Since less class hours are assigned in experiment teaching of course. The course practice teaching mode guided by projects is developed. The teaching practice proves that the students' practical operational ability and system design skill are successfully enhanced. It usefully elevates their independent design skills and expertise creativity as well.

\section{Acknowledgment}

Heilongjiang Province College Education Engineering Projects. Grant No: JG2012010282

Heilongjiang Province College Education Engineering Projects. Grant No: JG2013010302

\section{References}

[1] GU Bing-lin, Adhering to the Practice of Traditional Education to Strengthen Innovation Ability Training to Improve Students' Comprehensive Quality, TSIN GHUA JOURNAL OF EDUCATION, vol.27, no1, pp.1-3, February 2006.

[2] LIU Lei, FU Wei-li, Practice ability: Structure and Cultivation Measures, Education Science, vol.21, no.2, pp.1-5, Apr 2005

[3] DU Yu-xia, Ased on the Project of Undergraduate Practice Innovation Ability Training Research, Electrochemical Education Research, pp.3638. May 2011.

[4] SUN Guang-wei, HAN Ying, ZHOU Jing-hui, Undergraduate Innovation of Teaching and Test, Heilongjiang Pulp \& Paper, pp.59-61,March 2012.

[5] HUANG YA-ji, CUI Yun-he, XIAO Ge-lei, An Investigation Within the Undergraduates on Recognition of the Undergraduate Innovative Experiment Program, Journal of Educational Science of Hunan Normal University, vol.8, no.2, pp.113-115, March 2009.

[6] JIANG Tao, Colleges and Universities in the Teaching Process of Experiment Research and Discussion, Human Resource Management, December 2011, pp. 185-186.

[7] LI Jing-bo, Teaching Design Way of Thinking, Journal of Heilongjiang College of Education, Journal of Heilongjiang College of Education, vol.32, no.6, pp.46-47, Jun , 2013.

[8] LI Hui-min, The Practice of the Innovative Talents Cultivation in Colleges and Universities Experience and Path to Explore, Journal of Heilongjiang College of Education,vol.32, no.7, pp.10-12, Jul 2013. 